\title{
Correction to: Immunoglobulin free light chains: an inflammatory biomarker of diabetes
}

\author{
Akira Matsumori $^{1}$ [D $\cdot$ Toshio Shimada $^{2} \cdot$ Miho Shimada $^{3} \cdot$ Mark T. Drayson $^{4}$
}

Published online: 5 June 2020

C) Springer Nature Switzerland AG 2020

\section{Correction to: Inflammation Research}

https://doi.org/10.1007/s00011-020-01357-7

In the original publication of this paper contains some typographical errors in Table 1 and in the methods section. In Table 1, Controls $(N=75)$, not Diabetes $(N=77)$ and Column of FLC variables: $\mathrm{mg} / \mathrm{L}$ not $\mathrm{mg} / \mathrm{mL}$. In the First line of method; 77 patients, not 75 patients.

This has been corrected in this paper.

Publisher's Note Springer Nature remains neutral with regard to jurisdictional claims in published maps and institutional affiliations.

The original article can be found online at https://doi.org/10.1007/ s00011-020-01357-7.

Akira Matsumori

amat@kuhp.kyoto-u.ac.jp

1 Clinical Research Center, Kyoto Medical Center, 1-1

Fukakusa Mukaihata-cho, Fushimi-ku, Kyoto 612-8555,

Japan

2 Clinical Research Center, Shizuoka General Hospital, Shizuoka, Japan

3 VCL Laboratory, Osaka, Japan

4 The University of Birmingham, Birmingham, UK 